\title{
Differential effects of ibotenate lesions of the CA1 subfield of the hippocampus on a delayed-nonmatching-to-place task as a function of preoperative training in mice
}

\author{
YOON H. CHO, DANIEL BERACOCHEA, and ROBERT JAFFARD \\ Université de Bordeaux I, Talence, France
}

\begin{abstract}
This study examined the effects of ibotenate lesions of the hippocampal CA1 subfield on spatial working memory (delayed-nonmatching-to-place [DNMTP] task) as a function of the existence of preoperative training in mice. The task was varied in its level of difficulty according to either the number of interpolated arm visits (occupied delays) or the length of free time delays imposed between place sample presentation and subsequent recognition. Results indicate that when the tasks were first well learned and the CA1 subfield was subsequently lesioned, only slight impairments were observed during both reacquisition of the DNMTP rule and the problem containing five interpolated visits. When CA1 pyramidal cells were lesioned prior to any training, CA1lesioned subjects showed general performance deficits regardless of the delay studied (occupied or free). A shift from isolated rule task to the same task tested simultaneously with more difficult variants produced marked performance deficits even for the previously mastered DNMTP rule task. These results suggest that preoperative training reduces subsequent lesion-induced memory deficits and modifies the pattern of postoperative working-memory performance; lesions of the hippocampal CA1 field contribute to the impairments of not only mnemonic capability per se but also reference memory components of the DNMTP task underlying the procedural and cognitive demands required for correct performance of the task.
\end{abstract}

Anatomical and electrophysiological evidence has been obtained in support of the concept that the different subfields of the hippocampus may operate as a functional unit in spatial learning and memory processes (Jarrard, 1986). A number of studies have attempted to determine whether restricted damage to a particular subfield of the hippocampus is sufficient to produce mnemonic impairments similar to those observed following whole hippocampal lesions in animals, in particular, in the rodent. More recently, several neurotoxins have been developed to produce a selective loss of cells in restricted brain regions, while leaving intact fibers coursing through the area (Goldschmidt \& Steward, 1980; Jarrard, 1989). More precisely, intradentate injections of colchicine impair acquisition (Walsh, Schulz, Tilson, \& Shmechel, 1986) and retention (Jarrard, Okaiche, Steward, \& Goldschmidt, 1984; McLamb, Mundy, \& Tilson, 1988; McNaughton, Barnes, Meltzer, \& Sutherland, 1989) of a workingmemory task in the radial maze. Intrahippocampal injections of kainic or ibotenic acid induced an impairment in acquisition or retention of a spatial memory task in the

This study was supported by the Centre National de la Recherche Scientifique (CNRS) and the Fondation pour la Recherche Médicale. The authors wish to thank L. E. Jarrard for his evaluation of ibotenate CA1 field lesions, and T. Durkin for help in preparing this paper. Correspondence should be addressed to $Y$. H. Cho, who is now at the Department of Psychology, University of Utah, Salt Lake City, UT 84112 (fax: 801-581-5841). radial maze (Jarrard, 1986; Sutherland, Whishaw, \& Kolb, 1983; Whishaw, 1987) and in the Morris water maze (Whishaw, 1987). The fact of whether or not the animals were preoperatively trained, was identified as an important variable for the degree of postoperative impairment of performance (Gage, 1985; Jarrard, 1978, 1991).

Clinical observations have produced supplementary arguments in favor of the idea that limited damage to a subfield of the hippocampus would be sufficient for producing a significant amnesia (Zola-Morgan, Squire, \& Amaral, 1986). There exists a growing understanding of both the mechanism of neuronal degeneration and the memory impairment resulting from ischemic brain injury. In fact, this neuropathology results not only in a selective cell loss in certain brain structures, especially the whole anterior/posterior extent of the CA1 subfield of the hippocampus, but also a severe anterograde amnesia combined with mild retrograde amnesia (Cumming, Tomiyasu, Read, \& Benson, 1984; Volpe \& Hirst, 1983; Zola-Morgan et al., 1986). The relationship between memory impairments and the histopathological data led the authors to suggest that selective and limited damage to the CA1 subfield was primarily responsible for the memory deficits observed in ischemic patients.

An animal model of ischemia has been developed using transient bilateral occlusion of the carotid arteries (Pulsinelli, Brierley, \& Plum, 1982). Behavioral studies demonstrated that ischemic rats exhibited a permanent working- 
memory impairment in the radial maze (Kiyota, Miyamoto, \& Nagaoka, 1991; Volpe, Waczek, \& Davis, 1988), in the Morris water maze (Auer, Jensen, \& Whishaw, 1989; Hagan \& Beaughard, 1990; Kiyota et al., 1991 ), and in the T maze (Hagan \& Beaughard, 1990). However, the same animals presented only transient impairments (Gionet et al., 1991; Hagan \& Beaughard, 1990) or no deficits (Auer et al., 1989; Kiyota et al., 1991; Volpe et al., 1988) in reference memory tasks. Furthermore, an important observation was that the degree of postischemic learning and memory impairment was considerably reduced by preischemic training (Davis, Baranowski, Pulsinelli, \& Volpe, 1987; Volpe, Davis, \& Colombo, 1989).

Nevertheless, the behavioral data obtained using the ischemic rats presents some ambiguities. A certain degree of cell loss in caudoputamen, thalamus, and neocortical areas has frequently been observed outside the CA1 field in ischemia-damaged brain (Zola-Morgan et al., 1986). These data suggest that the extra-CA1 cell loss could contribute to the subsequent memory impairments.

The present study was designed to determine if selective destruction of the CAl pyramidal cells using ibotenic acid could produce significant memory impairments in a delayed-nonmatching-to-place task (DNMTP) in mice by using a radial maze. To determine whether preoperative training in the task influences the postoperative workingmemory performances, one half of the mice were trained prior to surgery and the other half were given only postoperative training.

\section{METHOD}

\section{Subjects}

Male mice of the BALB/c Jico strain, aged 10 to 12 weeks at the beginning of the experiment, were used as subjects. They were housed in individual cages with free access to dry food and water, in a climatized $\left(22^{\circ} \pm 1^{\circ} \mathrm{C}\right)$ colony room under a 12 -h light:dark schedule $(0700-1900 \mathrm{~h})$.

\section{Apparatus}

Working-memory testing was conducted using an automated and elevated eight-arm radial maze constructed of gray Plexiglas. The arms (50 cm long and $11 \mathrm{~cm}$ wide) radiated in a symmetrical fashion from a central circular platform $(30 \mathrm{~cm}$ in diameter). A circular food pellet tray was placed at the end of each arm. The maze was equipped with doors at the entrance of each arm and with photoelectric cells that allowed the detection of the animal's position in the maze. The information on the animal's behavior was constantly transmitted to a microcomputer that recorded the sequence of arm choices, running times, and choice latencies. The microcomputer program controlled both door opening and door closing according to the specifications of each particular test. A closed-circuit video system allowed the experimenter to observe the test in a neighboring room.

\section{Preoperative Training}

Habituation. The animals were first food deprived so that they exhibited a $15 \%$ weight loss at the time of testing. They were then habituated to the apparatus and the testing room. For this, the subjects were placed on the central platform of the maze with all doors opened so that they could freely explore the entire apparatus. The subjects were removed from the maze when each of the eight baited arms was visited and each of eight food pellets placed at the end of each arm was consumed. The animals were submitted to this

\begin{tabular}{|c|c|c|c|}
\hline \multirow[b]{2}{*}{$\begin{array}{l}\text { DNMTP } \\
\text { Problems }\end{array}$} & & Study Phase (Forced visits) & \multirow{2}{*}{$\begin{array}{l}\text { Test Phase } \\
\text { (Choices) }\end{array}$} \\
\hline & & $\begin{array}{l}\text { Sample - places }(A, B) \\
\text { Interposed interfering visits }(X) \\
\text { Delays }(\text { sec) }\end{array}$ & \\
\hline \multirow{3}{*}{$\begin{array}{l}\text { Occupied } \\
\text { Delays }\end{array}$} & P1 & $\mathbf{A} \cdot \mathbf{B}$ & $\begin{array}{l}\text { A } \cdot \text { C+ } \\
\text { B } \cdot \text { D+ }\end{array}$ \\
\hline & P3 & $\mathbf{A}: \mathbf{B}-\mathbf{X} \cdot \mathbf{X}$ & $\begin{array}{l}A \cdot C_{+} \\
B \cdot D_{+}\end{array}$ \\
\hline & P5 & $A \cdot B \cdot X \cdot X \cdot X \cdot X$ & $\begin{array}{l}\text { A } \cdot C_{+} \\
\text {B } \cdot D_{+}\end{array}$ \\
\hline \multirow{3}{*}{$\begin{array}{l}\text { Free } \\
\text { Delays }\end{array}$} & P2-0 & $\mathbf{A} \cdot \mathbf{B}-\underset{0 \mathrm{sec}}{H} \cdot \mathbf{X}$ & $\begin{array}{l}A \cdot C_{+} \\
B \cdot D_{+}\end{array}$ \\
\hline & P2-30 & $A-B-\left|-\frac{}{30 \sec }\right|-X$ & $\begin{array}{l}A \cdot C+ \\
B \cdot D+\end{array}$ \\
\hline & P2-60 & $A \cdot B \cdot I-\frac{}{60 \mathrm{sec}} \mid \cdot X$ & $\begin{array}{l}\text { A }-\mathbf{C}_{+} \\
\mathbf{B} \cdot \mathbf{D +}\end{array}$ \\
\hline
\end{tabular}

Figure 1. Delayed-nonmatching-to-place problems used for working-memory testing. The study phase (forced runs) consists of two sample places presented successively (A and B). These arm visits were followed either by a variable number of interposed visits $(X)$ or by one interposed run combined with variable time delays (in seconds). Each problem involved two choice runs (A-C and B-D) during which the mice were required to choose between the previously visited sample arms ( $A$ and $B$ ) and novel arms (C and D). Only the choice of the novel arm was reinforced. 
habituation phase over 4 consecutive days before being submitted to training for the acquisition of the delayed-nonmatching-to-place (DNMTP) rule.

DNMTP Rule Training. This task assessed the animal's ability to recognize a new place sample (arm) from another previously made familiar by a single presentation. Basically, each trial consisted of a study phase (forced run, sample place; see Figure 1) followed by a test phase (choice run). During the study phase, the mice were given two sequential forced runs. Once the animal returned to the central platform after entering the last arm, two doors-one giving access to the first arm that had been previously visited during the study phase and one giving access to an adjacent nonvisited armwere opened simultaneously (first choice). Once the animal had chosen one of these two arms and had returned to the central platform, the next pair of doors was opened (second choice) according to the same specification as that for the first choice (the second arm visited in the study phase and an adjacent novel one). On both choice runs, the animal was reinforced only when it entered into the arm that had not previously been visited during the study phase. Thus, in each trial, the animals were submitted to two successive choices. Sequences of forced runs and choice were selected in a quasirandom manner, such that for every test in which the correct arm was located on the left side of the sample-place, there was another choice for which this location was reversed. Thus, if a given animal systematically chose either the left or the right arm, choice accuracy would be only at chance level (50\% of correct responses). Daily sessions of eight trials, each separated by a 1-min intertrial interval, were continued until the subjects reached a criterion of $80 \%$ of correct responses for one session.

\section{Memory Testing}

Occupied delays (Problems P1, P3, and P5). After mastering the DNMTP rule, the animals were then submitted to a more complex memory test assessing the susceptibility of the subject to interference, as opposed to simple time-decay of the memory trace. The task was composed of three different problems, varying in their level of difficulty. This procedure was also composed of eight trials per daily session using three different problems delivered in a mixed fashion, and it was continued over 3 successive days. The study phase consisted of two (P1, for the DNMTP rule), four (P3), or six (P5) forced runs; the test phase consisted of two successive choices. In all cases, only the first two place samples visited were subsequently used for the choice responses. Thus, delayed recognition was tested after one, three, or five interfering forced runs interpolated between the initial place sample and its later recognition (see Figure 1).

Free delays (P2-0 sec, P2-30 sec, and P2-60 sec). The memory decay was also assessed in the free-delay condition. After coming out of the second arm visited in the study phase, the mice were confined on the central platform for 0,30 , or $60 \mathrm{sec}$. Following this imposed delay, the animal was given one further forced run before being submitted to two successive choices. This additional forced run was introduced to avoid response bias in relation to the animal's position at the time of the opening of the doors for recognition testing. Thus, delayed recognition was tested for two place samples per trial, with $0-, 30-$, or $60-\mathrm{sec}$ delays imposed. The preoperative training phase ended by 3 days of testing in the three free delays intermixed within each session (eight trials per day, and delay). The animals were then assigned to one of three subgroups on the basis of their preoperative performance levels of three measures studied: number of trials to acquire the rule, performance during occupied delays, and performance during free delays.

\section{Postoperative Testing}

The schedule used for preoperative training was also used for postoperative testing: the subjects were first trained on the DNMTP rule and were subsequently submitted to daily sessions of memory testing with the intermixed problems procedure. Analysis of performance for each of the problems was based on 32 observations per subject.

\section{Experimental Design}

In order to assess the effects of the lesion of the CAl field of the hippocampus on spatial learning and memory performance as a function of preoperative training, the subjects were divided into two groups: one group was given preoperative training and the other group was not.

As described above (and as is shown in Figure 2), preoperative training including habituation, DNMTP rule learning, and subsequent memory testing were carried out using a total of 17 mice. They were then divided, on the basis of their preoperative performance level, into three subgroups: a control group $(n=4)$, a shamoperated control group $(n=3)$, and a CA1-lesioned group $(n=10)$. After recovery from surgery, they were assessed for the reacquisition of DNMTP rule and their working-memory performance.

Fifteen naive mice were given only postoperatively training. They were randomly assigned to one of three subgroups-a control group $(n=5)$, a sham-operated group $(n=3)$, and a CA1-lesioned group $(n=7)$-and were submitted to surgery. After recovery, they were trained on the same postoperative schedule that was used for the preoperatively trained group, except that the postoperatively trained group was first submitted to the habituation phase before beginning rule training.

\section{Surgery}

The animals were first anesthetized with sodium penthiobarbital $(100 \mathrm{mg} / \mathrm{kg}$ i.p.) and placed in a stereotaxic frame (Kopf instrument). An incision was made in the scalp to expose the skull, and holes were drilled through the skull at the coordinates given in Table 1 . Ibotenic acid (IBO) was dissolved in phosphate buffered saline $(\mathrm{pH} .7 .4)$ at a concentration of $10 \mathrm{mg} / \mathrm{ml}$. Small quantities (20-40 $\mathrm{nl}$, see below) of IBO were injected in order to selectively lesion the entire CAl subfield of the hippocampus. The injections were carried out using a glass micropipette that was glued to the

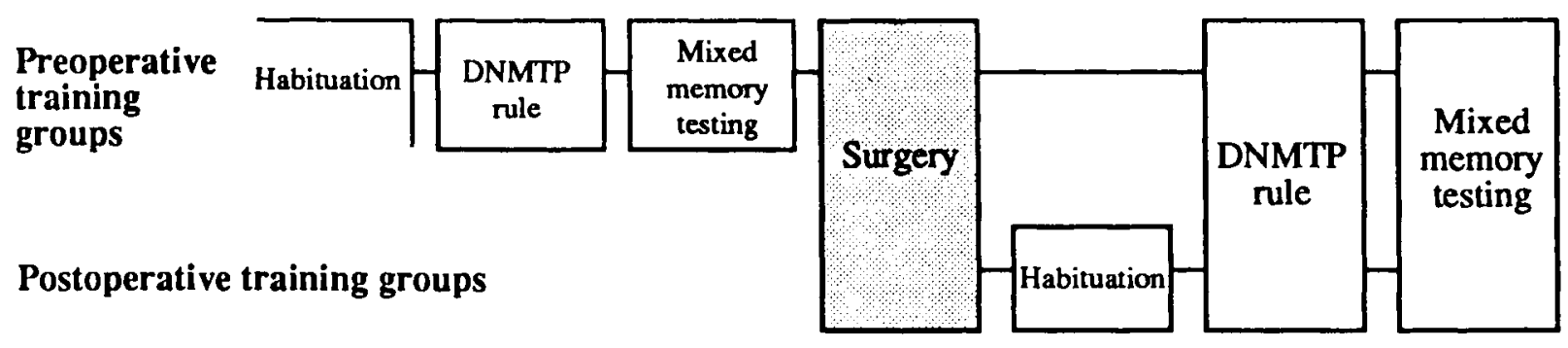

Figure 2. Experimental protocol used for spatial memary testing in the delayed-nonmatching-to-place tosk. 
Table 1

Stereotaxic Coordinates $(\mu \mathrm{m})$ and Volumes $(\mu \mathrm{I})$ of Ibotenic Acid Used for Lesioning the CA1 subfield of the Hippocampus

\begin{tabular}{cccc}
\hline Anteroposterior & Lateral & Vertical & Volume \\
\hline-1.6 & 0.7 & 0.8 & 0.015 \\
-2.1 & 1.0 & 1.0 & 0.02 \\
-3.0 & 2.0 & 1.3 & 0.01 \\
-3.0 & 3.5 & 1.7 & 0.03 \\
\hline
\end{tabular}

outlet of a 1-ml Hamilton syringe and that was mounted on the stereotaxic apparatus. After each injection, the pipette was left in place for $4 \mathrm{~min}$ to ensure diffusion of the neurotoxin; it was then raised slowly to prevent the solution from spreading back up the injection track. After completing the injections, the scalp was sutured and the animal was removed from the frame and replaced in its home cage. The sham-operated animals were submitted to the same surgical procedures but without being injected with the IBO solution (i.e., only the empty micropipette was introduced to the hippocampus). All animals that received sham operations and lesions were allowed 1 week of postoperative recovery.

\section{Histology}

Following the completion of behavioral testing, CA1-lesioned and sham-operated control animals were deeply anesthetized and perfused transcardially with a physiological saline solution followed by $10 \%$ formalin. The brains were removed from the skull and soaked in a $30 \%$ sucrose-formalin solution during $24 \mathrm{~h}$. They were then cut in a frontal plane at $30 \mu \mathrm{m}$ on a microtome. The thionin cell stain was used for microscopic examination of the extent and placement of lesions.

\section{Data Analysis}

The number of sessions required to reach the criterion for DNMTP rule learning criterion in each of the groups and the number of correct responses in the different working-memory problems for each group were analyzed using analysis of variance.

\section{RESULTS}

\section{Histology}

Careful examination of brain sections from the animals of the preoperative training group revealed an extensive and selective loss of cells in the intended area in 7 out of 10 lesioned mice (see Figure 3). Three animals from this group were discarded from subsequent behavioral analysis on the basis of either insufficient or misplaced lesions. The 7 remaining subjects exhibited mild cortical lesions in addition to the CAl cell loss. In the hippocampus, the CAl pyramidal cells were extensively destroyed at the anterior-mid level, whereas damage to posterior levels was limited to the dorsal portion of the hippocampus. There was a slight but inconsistent cell loss in the adjacent CA3 area and in the dentate gyrus, unilaterally at the mid level in 2 animals. A small amount of dorsal subiculum cell loss was observed in 4 animals.

Two out of 7 lesioned animals from the group without pretraining were eliminated from the analysis on the basis of too extensive lesions. Lesion of posterior CA1 cells was pronounced; cell loss in the dorsal area of the hippocampus was less extensive and occasionally partial. Three animals showed slight loss of CA3 cells. Some dorsal subiculum cells were also lost in 2 other animals (see Figure 3).

To summarize, all animals exhibited extensive bilateral lesions with damage predominantly affecting the CA1 area and to a degree of at least $70 \%$ of the anteroposterior extent of the field.

\section{Behavior}

Control animals and sham-operated control animals presented a very similar level of performance in all tasks (for all comparisons, $F_{\mathrm{S}}<1$ ). Their performances have been pooled for comparison with the CA1-lesioned subjects.

Acquisition and reacquisition of the DNMTP rule. Results are represented in Figure 4. During preoperative training, the animals trained for the first time required a mean of 3.86 daily sessions to reach the criterion. There were no significant between-group differences (i.e., controls and CA1 groups, n.s.). After CA1 lesioning, preoperatively trained animals required significantly more sessions to reattain the criterion than did controls $[M \mathrm{~s}=2.4$ vs. $1.0 ; F(1,12)=2.2, p=.048]$. Relative to their control group, CA1-lesioned subjects without preoperative training also required more sessions to achieve the crite-

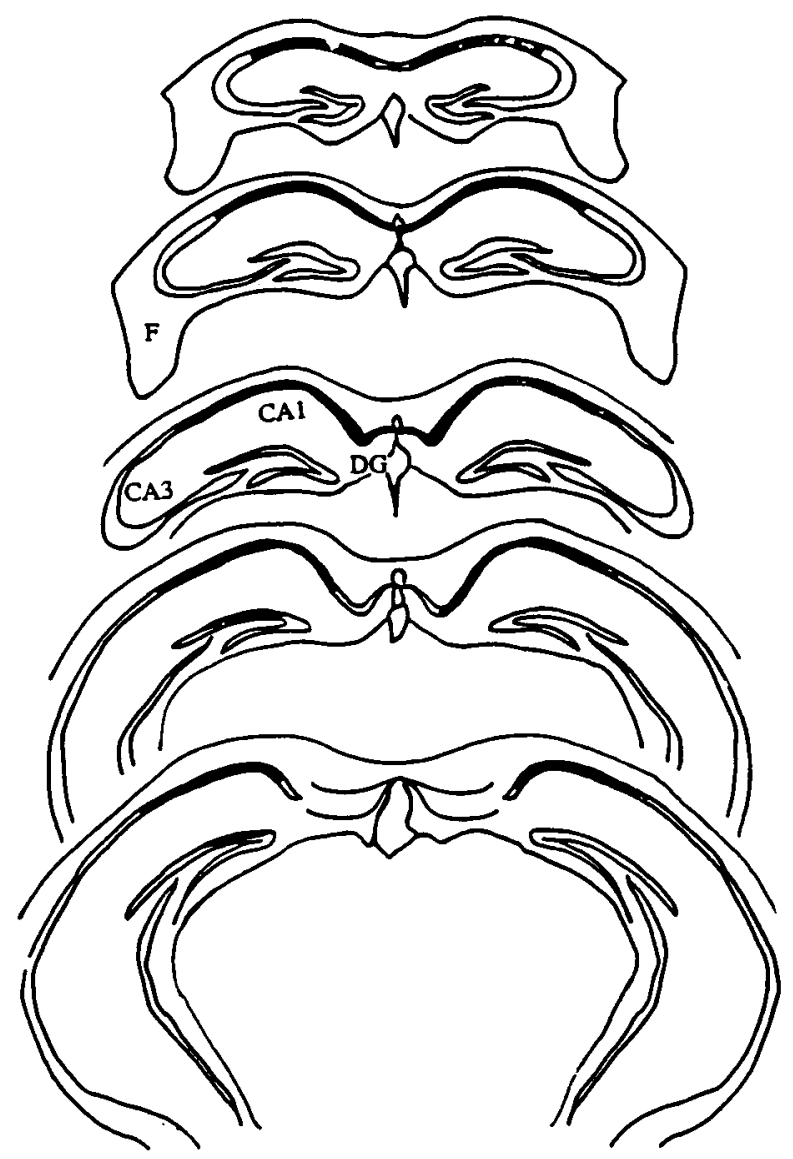

Figure 3. Schematic coronal section (from anterior to posterior level) representing a typical CA1 lesion (darkened area over pyramidal and granule cells). 


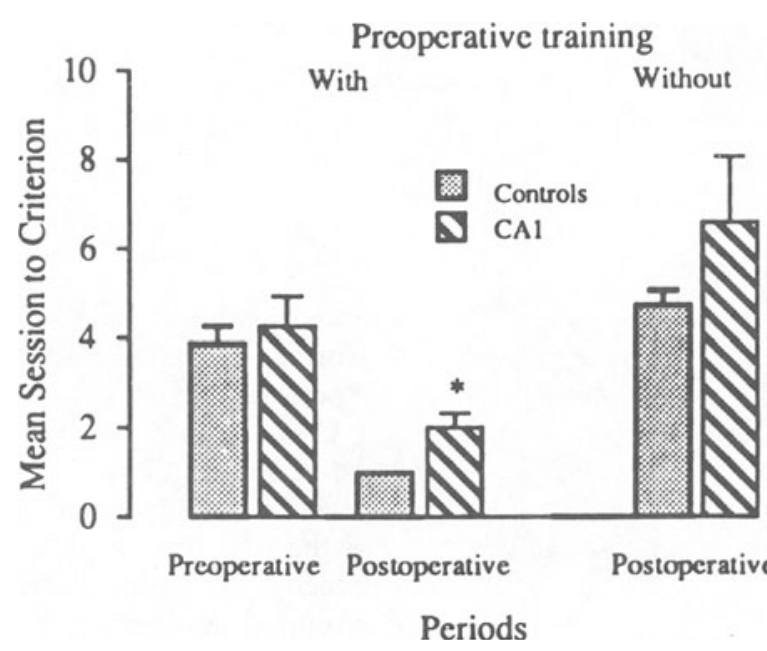

Figure 4. Mean number of sessions $( \pm S E M)$ to achieve criterion during both preoperative and postoperative periods in control and CA1-lesioned groups with and without preoperative training. *Significantly different from respective controls.

rion (6.6 vs. 4.7); however, this difference was not statistically significant $[F(1,11)=1.54, p>.10]$, and preoperative training reduced the number of sessions in both CA1-lesioned $[F(1,10)=8.33, p=.01]$ and control controls $[F(1,13)=124.09, p=.0001]$.

Performance on isolated versus mixed P1 problems. As shown in Figure 5, CAl-lesioned subjects with preoperative training exhibited a slight increase in performance, similar to that observed for controls, when shifted from isolated P1 (performance on the last DNMTP rule acquisition session) to mixed (i.e., with P3 and P5) prob- lems [group $\times$ situation interaction, $F(1,12)=0.07$ ]. In contrast, relative to their control group, experimental subjects without preoperative training exhibited a significant impairment of performance when shifted from the first to the second situation [group $\times$ situation interaction, $F(1,12)=8.1, p=.015]$. Thus, starting from very similar levels of performance on isolated P1 problems $\mathbf{8 3 . 8 \%}$ vs. 83.0\%), CAl-lesioned animals differed when shifted to the mixed situation, depending on whether (trained, $87.5 \%$ ) or not (nontrained, $73.1 \%$ ) they had undergone preoperative training [pretraining $\times$ situation interaction, $F(1,10)=8.202, p=.016$.

Performance on P1 to P5 problems (mixed procedure). Results summarized in Table 2 show that, relative to the performance of their respective control groups, the performance of CA1-lesioned subjects both with (control, 77.8\%; lesion, 72.0\%) and without (control, 70.6\%; lesion, $62.5 \%$ ) preoperative training exhibited a significant impairment in their overall performance lgroup effect, $F(1,12)=7.9, p=.016$, and $F(1,11)=9.9, p=.009$, respectively], but without any significant group $\times$ problem difficulty interaction $[F(2,24)=0.631$ and $F(2,22)=$ 0.864 , respectively]. Moreover, the relative impairment produced by $\mathrm{CA} 1$ lesion did not depend on pretraining [group $\times$ pretraining interaction, $F(1,23)=0.483$ ]

Performance on P2-0 sec to $60 \mathrm{sec}$ (mixed procedure). Results are summarized in Table 3 . Relative to their control groups $(67.9 \%)$, CA1-lesioned animals with preoperative training $(66.2 \%)$ exhibited no significant impairment in their overall performance [group effect, $F(1,12)=0.26$ ], a result in sharp contrast to that obtained for animals without pretraining [trained, $66.2 \%$; nontrained, $58.5 \% ; F(1,11)=7.5, p=.018]$. As shown in Table 3, the main difference between these two condi-

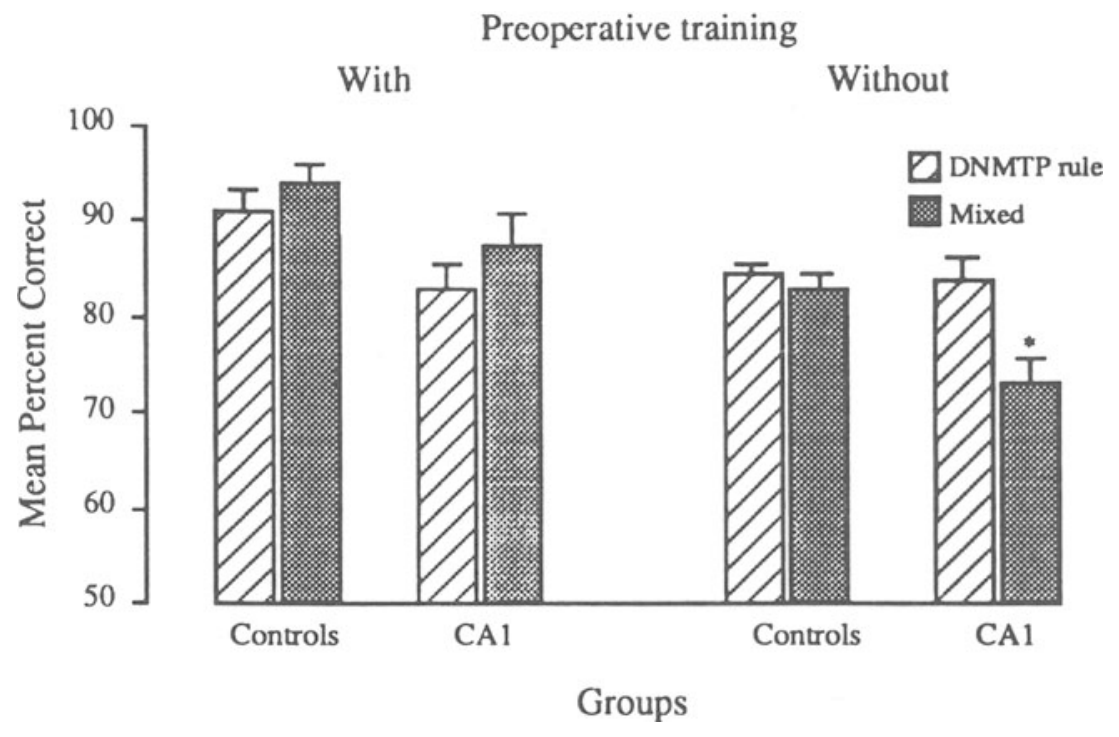

Figure 5. Postoperative performance on the P1 problem (mean percent correct \pm SEM) in control and CA1-tesioned groups during the last delayed-nonmatching-to-place (DNMTP) rule acquisition session and the mixed session. "Significantly different from performance in the DNMTP rule. 
Table 2

Postoperative Performance (Mean Percent Correct \pm SEM) During the

Last DNMTP Rule Acquisition Session (Isolated Condition) and on Mixed P1, P3, and P5 Problems in CA1-Lesioned and Control Groups With and Without Preoperative Training

\begin{tabular}{|c|c|c|c|c|c|c|c|c|c|}
\hline & \multirow{2}{*}{\multicolumn{2}{|c|}{$\begin{array}{c}\text { Isolated } \\
\text { P1 }\end{array}$}} & \multicolumn{6}{|c|}{ Mixed } & \multirow{3}{*}{$\begin{array}{c}\text { Pooled } \\
M\end{array}$} \\
\hline & & & \multicolumn{2}{|c|}{ P1 } & \multicolumn{2}{|c|}{ P3 } & \multicolumn{2}{|c|}{ P5 } & \\
\hline & $M$ & $S E M$ & $M$ & $S E M$ & $M$ & $S E M$ & $M$ & SEM & \\
\hline \multicolumn{10}{|c|}{ With Preoperative Training } \\
\hline $\begin{array}{l}\text { Controls } \\
\text { CA1 }\end{array}$ & $\begin{array}{l}91.1 \\
83.0\end{array}$ & $\begin{array}{l}2.3 \\
2.6\end{array}$ & $\begin{array}{l}94.2 \\
87.5\end{array}$ & $\begin{array}{l}1.7 \\
3.2\end{array}$ & $\begin{array}{l}74.6 \\
72.3\end{array}$ & $\begin{array}{l}4.0 \\
2.3\end{array}$ & $\begin{array}{l}64.7 \\
56.3 *\end{array}$ & $\begin{array}{l}2.8 \\
1.8\end{array}$ & $\begin{array}{l}77.8 \\
72.0^{*}\end{array}$ \\
\hline \multicolumn{10}{|c|}{ Without Preoperative Training } \\
\hline $\begin{array}{l}\text { Controls } \\
\text { CA1 }\end{array}$ & $\begin{array}{l}84.4 \\
83.8\end{array}$ & $\begin{array}{l}1.2 \\
2.5\end{array}$ & $\begin{array}{l}82.8 \\
73.1 \dagger\end{array}$ & $\begin{array}{l}1.8 \\
2.6\end{array}$ & $\begin{array}{l}68.8 \\
59.4^{*}\end{array}$ & $\begin{array}{l}2.6 \\
1.7\end{array}$ & $\begin{array}{l}60.2 \\
55.0\end{array}$ & $\begin{array}{l}2.6 \\
1.6\end{array}$ & $\begin{array}{l}70.6 \\
62.5 \dagger\end{array}$ \\
\hline
\end{tabular}

*Significantly different from controls, $p<.05$. †Significantly different from controls, $p<.01$.

Table 3

Performance Recorded Postoperatively Using Three Free Delays $(0,30$, and $60 \mathrm{sec})$ in the Mixed Procedure for Control and CA1-Lesioned Groups With and Without Preoperative Training

\begin{tabular}{|c|c|c|c|c|c|c|c|c|}
\hline & \multirow[b]{3}{*}{$n$} & \multicolumn{6}{|c|}{ Mixed } & \multirow{3}{*}{$\begin{array}{c}\text { Pooled } \\
\qquad M\end{array}$} \\
\hline & & \multicolumn{2}{|c|}{$\mathrm{P} 2-0 \mathrm{sec}$} & \multicolumn{2}{|c|}{$\mathrm{P} 2-30 \mathrm{sec}$} & \multicolumn{2}{|c|}{$\mathrm{P} 2-60 \mathrm{sec}$} & \\
\hline & & $M$ & $S E M$ & $M$ & $S E M$ & $M$ & $S E M$ & \\
\hline \multicolumn{9}{|c|}{ With Preoperative Training } \\
\hline Controls & 7 & 81.7 & 2.4 & 63.4 & 1.6 & 58.5 & 3.0 & 68.8 \\
\hline CAl & 7 & 77.7 & 3.6 & 62.9 & 3.8 & 58.0 & 5.6 & 66.2 \\
\hline \multicolumn{9}{|c|}{ Without Preoperative Training } \\
\hline Controls & 8 & 72.7 & 2.3 & 64.9 & 3.0 & 60.9 & 2.1 & 66.2 \\
\hline CAl & 5 & $61.3^{*}$ & 3.8 & 52.5 & 5.5 & 61.9 & 1.8 & $58.5^{*}$ \\
\hline
\end{tabular}

*Significantly different from controls, $p<.05$.

tions resulted from performance recorded on the $\mathrm{P} 2-0$-sec problem. Indeed, relative to their respective scores on the isolated P1 problem, pretrained lesioned and control mice exhibited the same changes in performance levels when tested on the P2-0-sec problem [group $\times$ situation interaction, $F(1,12)=0.52$ ]. This contrasts with results obtained in CA1-lesioned subjects for which this situationinduced shift was significantly exacerbated (from $83.0 \%$ to $61.3 \%$ ), relative to the decrease in performance observed in controls (from $84.4 \%$ to $72.7 \%$ ) [group $\times$ situation interaction, $F(1,11)=4.9, p=.047]$. In other words, once again, preoperative training significantly attenuated this situation-induced shift decrease in performance of CA1-lesioned subjects [pretraining $\times$ situation interaction, $F(1,10)=6.9, p=.024]$.

\section{DISCUSSION}

These results show that, as a whole, extensive ibotenate lesions of the hippocampal CA1 field induced significant impairments of performance in a DNMTP task. Relative to their respective control groups, preoperatively trained CA1-lesioned subjects were less impaired than were those without preoperative training. In this sense, CA1 lesions seemed to exacerbate impairments due to the absence of pretraining. Thus, when shifted from rule problem given in isolation to rule problem mixed with new (and more difficult) ones (i.e., P3 and P5, memory task), CA1lesioned subjects without pretraining exhibited significant impairments in P1 (as well as in P3 and P5) recognition performance, relative to either their respective control or CAl-lesioned animals trained preoperatively. More precisely, they exhibited a deficit that was independent of problem difficulty (occupied and free delay), revealing performance, but not memory, deficits.

The results obtained raise two fundamental and methodological questions about the experimental procedures used in DNMTS tasks in the literature independent of the site chosen for lesions. The first problem is related to the degree of preoperative training. The extent of preoperative task mastery has been observed to result in a corresponding attenuation of the postoperative performance deficits in monkeys with combined removal of the hippocampus and amygdala (Mishkin, 1978; Murray \& Mishkin, 1984). The second problem concerns the presentation procedure for the different problems, varying in either the level of task difficulty or the delay. The intermixed presentation procedure of different free delays produced delay-independent performance deficits in pretrained monkeys with the transection of the temporal stem (Cirillo, Horel, \& George, 1989), in nontrained human amnesics (Sidman, Stoddard, \& Mohr, 1968; Squire, Zola-Morgan, 
\& Chen, 1988), and in monkeys with a hippocampal lesion (Zola-Morgan \& Squire, 1986), whereas the progressive presentation procedure revealed delay-dependent memory deficits in nontrained hippocampal monkeys (Zola-Morgan \& Squire, 1986), in monkeys with combined damage to hippocampus and amygdala (ZolaMorgan, Squire, \& Mishkin, 1982), and in monkeys with lesions to the parahippocampal cortex (Zola-Morgan, Squire, Amaral, \& Suzuki, 1989).

These different experimental procedures might induce different patterns of postoperative performance in the DNMTP task. The most frequently used training procedure is as follows: The subjects are first trained in the basic rule learning. Upon completion of the rule acquisition, the subjects are classically submitted to memory testing using progressively increasing delays between presentation and recognition, without any additional training at the longer delays (Zola-Morgan \& Squire, 1986). As has been suggested by Cirillo et al. (1989), this experimental procedure advantages the performances at short delays (delay used during rule learning task), but not the longer ones for which the animal was never adequately trained before. This procedure would contribute to a disproportionate estimation of performance impairment for only the long delay intervals.

In our experimental condition, the animals were first trained on the DNMTP rule and were then submitted to daily sessions in which three different (occupied or free) delays were assessed in a mixed fashion. If we tested performance by presenting only long delays (increasing the amount of interpolated information between presentation and recognition) without daily inclusion of the previously mastered rule problem, we could erroneously conclude that the CA1 field damage induces mnemonic impairment in the DNMTP task. However, the performance levels in the rule task in nonpretrained CA1 animals force us to consider that the deficits in P3 and P5 could be due not only to the long delay (problem difficulty) but also to the decreased capability in applying the rule of the task in the long-delay problems never encountered before (Jaffard, Beracochea, \& Cho, 1991). The impairments observed both in rule learning and in applying the previously acquired rule in different situations in CA1-lesioned mice are in agreement with the view that, in rodents, the hippocampus is critically involved in spatially organized behaviors (Barnes, 1988; O'Keefe \& Nadel, 1978) and/or in the ability to use flexible representations of previously acquired memories in novel situations (Eichenbaum, Mathews, \& Cohen, 1989; Eichenbaum, Stewart, \& Morris, 1990).

Similar results and conclusions based on DNMTS procedures were reported in monkeys with transection of the fornix. Gaffan (1974) observed significant delaydependent memory impairments in the fornix-transected monkey. However, these memory deficits did not appear if the animals were given preoperative training on the same task used for a postoperative testing (Gaffan, Gaffan,
\& Harrison, 1984; Gaffan, Shields, \& Harrison, 1984). Gaffan (1985) concluded that the DNMTS deficits might be due to the change from the conditions of original learning rather than the retention interval as such. The same conclusion was reached by Saunders and Weiskrantz (1989), showing that following fornix lesions, monkeys were unable to express their knowledge about objectobject associations outside the context in which it was originally acquired.

In view of the deficits observed in nontrained CA1lesioned animals, one can conclude that the hippocampal system is critical for the implementation of the rule over different delays and for successful execution of the task. This type of memory for invariant rules, which is acquired progressively via repeated experience, is akin to semantic memory (Tulving, 1983), reference memory (Olton, Becker, \& Handelmann, 1979), knowledge-based memory (Kesner, 1986), and abstract memory (Oakley, 1983). However, CA1 lesions in preoperatively trained animals did produce specific memory deficits, as evidenced by the deficit observed in the P5 problem, but not in the easier ones requiring less mnemonic demand. The same lesion in the nontrained subjects could primarily interfere with the capability of applying the task rule to different experimental situations, which, in turn, leads to an overall disruption of performance in the DNMTP task.

The fact that preoperative training attenuates the postoperative working-memory impairments suggests that the preoperatively trained animals could execute the spatial working-memory task in a manner different from that of the postoperatively trained subjects as a result of the remains of previous experience (e.g., established spatial representations, applying the rule to the task). The state of the animal in terms of the amount of prior training received may have important functional implications for the interpretation of any eventual memory impairments observed. As previously mentioned by a number of authors (e.g., Kesner, 1986; Morris, 1983), for the majority of the tasks that are routinely used in studies of memory and learning in animals, two forms of memory-reference (semantic) versus working (episodic) memory-will constantly interact with each other throughout the learning of a given task. The proportional contribution of one type of memory relative to the other will undoubtedly vary as a function of the stage of acquisition of the task. Furthermore, the neuronal substrates underlying DNMTP task performance might shift from the hippocampal region to an extrahippocampal site as a function of increasing mastery of the task. Previous data have in fact suggested an extended but time-limited role of the hippocampal formation (Cho, Beracochea, \& Jaffard, 1991; Zola-Morgan \& Squire, 1990) in retention performances, regardless of the type of memory task studied.

In conclusion, CA1 lesions produce deficits in a DNMTP task by causing a slight memory impairment at the longest occupied delay (in P5). The evidence for this sensitivity was, however, observable only when the ani- 
mals were preoperatively trained. In addition, the same ibotenate CA1 lesion appears to interfere not only with episodic memory but also with reference memory when the animals have not possessed any preoperative experience in the task. This interaction between the two forms of memory (Ridley \& Baker, 1991) and their spatiotemporal evolution could therefore indirectly explain the different patterns of impairment presently observed in trained or nontrained CA1-lesioned subjects.

\section{REFERENCES}

Auer, R. N., Jensen, M. L., Whishaw, I. Q. (1989). Neurobehavioral deficits due to ischemic brain damage limited to half of the CA1 sector of the hippocampus. Journal of Neuroscience, 9 , 1641-1647.

BARNES, C. A. (1988). Spatial learning and memory processes: The search for their neurobiological mechanisms in the rat. Trends in Neurosciences, 11, 163-169.

Cho, Y. H., Beracochea, D., \& JafFard, R. (1991). Temporally graded retrograde and anterograde amnesia following ibotenic entorhinal cortex lesion in mice. Society for Neuroscience Abstracts, 17, 1045.

Cirillo, R. A., Horel, J. A., \& George, P. J. (1989). Lesions of the anterior temporal stem and the performance of delayed match-to-sample and visual discriminations in monkeys. Behavioural Brain Research, 34, 55-69.

Cumming, J. L., Tomiyasu, U., Read, S., Benson, D. F. (1984). Amnesia with hippocampal lesions after cardiopulmonary arrest. Neurology, 34, 679-681.

Davis, H. P., Baranowski, J. R., Pulsinelu, W. A., \& Volpe, B. T. (1987). Retention of reference memory following ischemic hippocampal damage. Physiology \& Behavior, 39, 783-786.

Eichenbaum, H., Mathews, P., \& Cohen, N. J. (1989). Further studies of hippocampal representation during odor discrimination learning. Behavioral Neuroscience, 103, $1207-1216$.

Eichenbaum, H., Stewart, C., \& Morris, R. G. M. (1990). Hippocampal representation in place learning. Journal of Neuroscience, 10 , 3531-3542.

GAFFAN, D. (1974). Recognition impaired and association intact in the memory of monkeys after transection of the fornix. Journal of Comparative \& Physiological Psychology, 86, 1100-1109.

GAFFAN, D. (1985). Hippocampus: Memory, habit and voluntary movement. Philosophical Transactions of the Royal Society of London, B308, 87-99.

GafFan, D., GafFan, E. A., Harrison, S. (1984). Effects of fornix transection upon spontaneous and trained non-matching by monkeys. Quarterly Journal of Experimental Psychology: Comparative \& Physiological Psychology, 36B, 285-303.

GafFAN, D., Sheilds, C., \& HARrison, S. (1984). Delayed matching by fornix-transected monkeys: The sample, the push and the bait. Quarterly Journal of Experimental Psychology: Comparative \& Physiological Psychology, 36B, 305-317.

GAGE, P. D. (1985). Performance of hippocampectomized rats in a reference/working-memory task: Effects of preoperative versus postoperative training. Physiological Psychology, 13, 235-242.

Gionet, T. X., Thomas, J. D., Warner, D. S., GoodletT, C. R., WASSERMAN, E. A., WEST, J. R. (1991). Forebrain ischemia induces selective behavioral impairments associated with hippocampal injury in rats. Stroke, 22, 1040-1047.

Goldschmid, R. B., \& Steward, O. (1980). Preferential neurotoxicity of colchicine for granule cells of the dentate gyrus of the adult rat. Proceedings of the National Academy of Sciences, 77, 3047-3051.

HAGAN, J. J., \& BEAUGHARD, M. (1990). The effects of forebrain ischaemia on spatial learning. Behavioural Brain Research, 41, 151-160.

JAFFARD, R., BERACOCHEA, D., CHO, Y. (1991). The hippocampalmamillary system: Anterograde and retrograde amnesia. Hippocampus, 1, 275-278.

JARRARD, L. E. (1978). Selective hippocampal lesions: Differential effects on performance by rats of a spatial task with preoperative versus postoperative training. Journal of Comparative \& Physiological Psychology, 92, 119-127.

JARRARD, L. E. (1986). Selective hippocampal lesions and behavior: Implications for current research and theorizing. In R. Isaacson \& K. H. Pribram (Eds.), The hippocampus (Vol. 4, pp. 93-126). New York: Plenum.

JARRARD, L. E. (1989). On the use of ibotenic acid to lesion selectively different components of the hippocampal formation. Journal of Neuroscience Methods, 29, 251-259.

JARRARD, L. E. (1991). On the neural bases of the spatial mapping system: Hippocampus vs. hippocampal formation. Hippocampus, 1, 236-239.

Jarrard, L. E., OKaiche, H., Steward, O., Goldschmidt, R. B. (1984). On the role of hippocampal connections in the performance of place and cue tasks: Comparisons with damage to hippocampus. Behavioral Neuroscience, 95, 946-954.

KESNER, R. P. (1986). Neurobiological views of memory. In J. L. Martinez \& R. P. Kesner (Eds.), Leaming and memory: A biological view (pp. 399-438). Orlando: Academic Press.

Kiyota, Y., MiYamoto, M., Nagnoka, A. (1991). Relationship between brain damage and memory impairment in rats exposed to transient forebrain ischemia. Brain Research, 538, 295-302.

McLamb, R. L., Mundy, W. R., \& Tilson, H. A. (1988). Destruction of dentate gyrus cells with colchicine interferes with the acquisition and retention of a working memory task in rats. Neurotoxicology \& Teratology, 9, 521-528.

McNaughton, B. L., Barnes, C. A., Meltzer, J., \&utherland, R. J. (1989). Hippocampal granule cells are necessary for normal spatial learning but not for spatially-selective pyramidal cell discharge. Experimental Brain Research, 76, 485-496.

Mishkin, M. (1978). Memory in monkeys severely impaired by combined but not by separate removals of amygdala and hippocampus. Nature, 273, 297-298.

MorRIs, R. G. M. (1983). An attempt to dissociate "spatial-mapping" and "working-memory" theories of hippocampal function. In W. Seifert (Ed.), Neurobiology of the hippocampus (pp. 405-432). New York: Academic Press.

MURRAy, E. A., Mishkin, M. (1984). Severe tactual as well as visual memory deficits following combined removal of the amygdala and hippocampus in monkeys. Journal of Neuroscience, 4, 2565-2580.

OAKLEY, D. A. (1983). The varieties of memory: A phylogenetic approach. In A. Mayes (Ed.), Memory in animals and humans (pp. 2082). New York: Van Nostrand Reinhold.

O'KeEFE, J., \& NADEL, L. (1978). The hippocampus as a cognitive map. Oxford: Clarendon Press.

Olton, D. S., Becker, J. T., \& Handelmann, G. E. (1979). Hippocampus, space and memory. Behavioral \& Brain Science, 2, 487-533.

Pulsinelli, W., Brierley, J., \& Plum, F. (1982). Temporal profile of neuronal damage in model of transient forebrain ischemia. Annals of Neurology, 11, 491-498.

RIDLEY, R. M., BAKER, H. F. (1991). A critical evaluation of monkey models of amnesia and dementia. Brain Research Reviews, 16 , 15-37.

Saunders, R. C., \& Weiskrantz, L. (1989). The effects of fomix transection and combined fornix transection, mammillary body lesions and hippocampal ablations or object-pair association memory in the rhesus monkey. Behavioural Brain Research, 35, 85-94.

Sidman, M., Stoddard, L. T., \& MoHR, J. P. (1968). Some additional quantitative observations of immediate memory in a patient with bilateral hippocampal lesions. Neuropsychologia, 6, 245-254.

Squire, L. R., Zola-Morgan, S., \& Chen, K. S. (1988). Human amnesia and animal models of amnesia: Performance of amnesic patients on tests designed for the monkey. Behavioral Neuroscience, 102, $210-221$.

Sutherland, R. J., Whishaw, I. Q., Kolb, B. (1983). A behavioural analysis of spatial localisation following electrolytic kainate or colchicine induced damage to the hippocampal formation in the rat. Behavioural Brain Research, 7, 133-153.

Tulving, E. (1983). Elements of episodic memory. Oxford: Clarendon. VolPe, B. T., DAvis, H. P., \& Colombo, P. J. (1989). Preoperative training modifies radial maze performance in rats with ischemic hippocampal injury. Stroke, 20, 1700-1706. 
VolPE, B. T., \& HiRST, W. (1983). The characterization of an amnesic syndrome following hypoxic ischemic injury. Archives of Neurology, 40, 436-440.

VolPE, B. T., WACZEK, B., \& DAvis, H. P. (1988). Modified T-maze training demonstrated dissociated memory loss in rats with hippocampal injury. Behavioural Brain Research, 27, 259-268.

Walsh, T. J., Schulz, D. W., Tilson, H. A., \& Shmechel, D. E. (1986). Colchicine-induced granule cell loss in rat hippocampus: Selective behavioral and histological alterations. Brain Research, 398, 23-36.

Whishaw, I. Q. (1987). Hippocampal granule cell and CA3-4 lesions impair formation of a place learning-set in the rat and induce reflex epilepsy. Behavioural Brain Research, 24, 59-72.

Zola-Morgan, S., SQuire, L. R. (1986). Memory impairment in monkeys following lesions limited to the hippocampus. Behavioral Neuroscience, 100, 155-160.

Zola-Morgan, S., \& SQUIRE, L. R. (1990). The primate hippocampal formation: Evidence for a time-limited role in memory storage. Science, 250, 288-290.

Zola-Morgan, S., Squire, L. R., \& Amaral, D. G. (1986). Human amnesia and the medial temporal region: Enduring memory impairment following a bilateral lesion limited to the CAl field of hippocampus. Journal of Neuroscience, 6, 2950-2967.

Zola-Morgan, S., Squire, L. R., Amaral, D. G., Suzuki, W. A. (1989). Lesions of perirhinal and parahippocampal cortex that spare the amygdala and hippocampal formation produce severe memory impairment. Journal of Neuroscience, 9, 4355-4370.

Zola-Morgan, S., Squire, L. R., Mishin, M. (1982). The neuroanatomy of amnesia: Amygdala-hippocampus versus temporal stem. Science, 218, 1337-1339.

(Manuscript received April 7, 1992; revision accepted for publication July 24,1992 .) 